\title{
Epidemiology of the dementias: recent developments and new approaches
}

\author{
$C M$ van Duijn
}

\begin{abstract}
Dementia is an important cause of disability in elderly people. Given the increase in the proportion of elderly people in most countries, the number of patients with dementia will rise and the care of these patients will have a growing impact on the healthcare system and society. The past decade has seen many successes in epidemiological studies of the aetiology of chronic disorders including cardiovascular disease, cancer, and osteoporosis. In this review, new developments in the epidemiology of the dementias are discussed. Descriptive studies of the occurrence of dementia across different populations and time periods as well as studies of risk factors for dementia are reviewed. Dementia is a syndrome that can be caused by many conditions. As Alzheimer's disease is the predominant cause of dementia, accounting for at least half of the cases in most populations, epidemiological research has focused on this disorder.
\end{abstract}

\section{Geographical trends}

Cross cultural comparison of the occurrence of disease has led to important clues to risk factors implicated in chronic disorders such as cardiovascular disease and cancer. The number of epidemiological studies on dementia is still small compared with these other chronic disorders. However, several community based studies have considered the prevalence of dementia - that is, the number of patients with dementia alive in a defined population and time frame. These studies have been reviewed recently. ${ }^{1-3}$ An important limitation of prevalence studies is that differences in occurrence and survival of disease in a population cannot be distinguished. They are of little value when comparing the risk of dementia across populations. Community based studies of the incidence of dementia-that is, the number of patients that are newly diagnosed in a defined population and time frame-are to be preferred.

At present, there are only a limited number of such studies available. ${ }^{4-17}$ The table shows their general characteristics. In all studies, the diagnosis of dementia and Alzheimer's disease was in accordance with currently accepted criteria. ${ }^{18-19}$ Figures 1 and 2 present age specific incidence rates of dementia and Alzheimer's disease. Up to the age of 75 years, there is little evidence for a large variation in dementia and Alzheimer's disease between studies. The incidence of Alzheimer's disease seems to be increased in the east Boston study ${ }^{16}$; however, this may be explained by the fact that the diagnosis of Alzheimer's disease was based primarily on psychometric testing. ${ }^{4}$ There is considerable variation in the incidence of dementia and Alzheimer's disease between populations after the age of 75 years, which is not likely to be a result of differences in diagnostic criteria given the lack of variation up to the age of 75 years. However, the few subjects at risk in some studies, methodological problems related to non-response, competing mortality, and comorbidity complicating the diagnosis make it doubtful whether these variations truly reflect a difference in incidence of dementia between populations.

There is some evidence that the relative proportion attributed to the most common subtypes, Alzheimer's disease and vascular dementia, differ between populations. ${ }^{20}$ In studies of Caucasian populations from Europe and North America, over $50 \%$ of all patients with dementia were attributed to Alzheimer's disease compared with only $12-30 \%$ to vascular causes. ${ }^{20}$ In Asian populations, vascular dementia was found to be underlying the dementia in up to $60 \%$ of the patients. ${ }^{20}$ In the 
Figure 1 Comparison of age specific incidence of dementia in community based studies in Europe (A) and elsewhere (B).
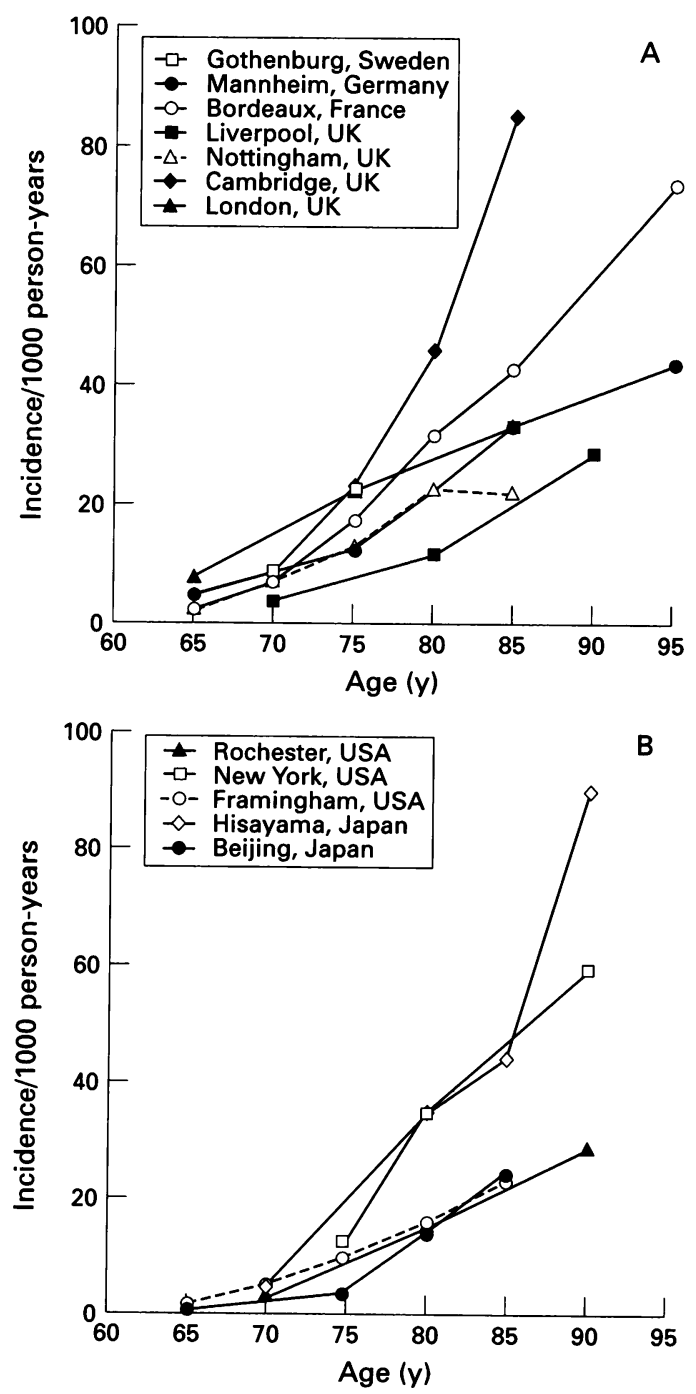

Figure 2 Comparison of age specific incidence of Alzheimer's disease in community baséd studies.

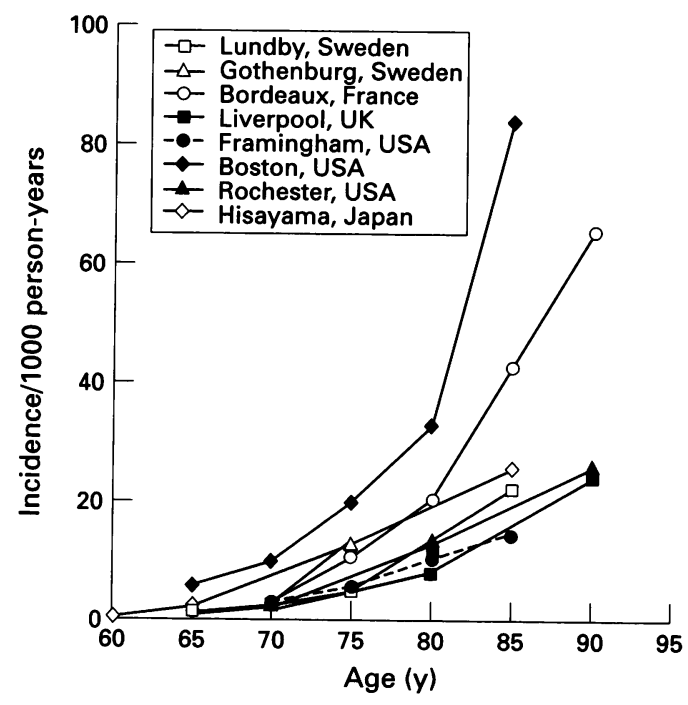

two Japanese studies of incident patients, vascular dementia constituted $40 \%$ and $60 \%$ of all dementia. ${ }^{71}$ As the incidence of Alzheimer's disease was similar across populations, this suggests that the incidence of vascular dementia may be increased in Asian populations. $^{717}$ It may be speculated that genetic or environmental factors underlie the differences in incidence of vascular dementia across populations. However, there are two important considerations. Firstly, vascular dementia may be underestimated in Caucasian populations as some prevalence studies in Caucasians have reported a proportion of vascular dementia up to $50 \% .^{421}$ Secondly, an intrinsic problem when comparing different populations for the relative proportion of Alzheimer's disease and vascular dementia is the fact that the diagnosis of vascular dementia is based on the presence of dementia and cerebrovascular disease. The diseases may be related, but no causal relation between the vascular pathology and the dementia can be established in patients. This may bias the comparison of populations with different rates of vascular disease, as this would inevitably predict a higher proportion of vascular dementia in populations with a higher rate of vascular disease. As the clinical diagnosis of Alzheimer's disease is based on the exclusion of other causes of dementia, including vascular dementia, this may also affect the prevalence of Alzheimer's disease. Similar problems relate to the comparison of the frequency of subtypes of dementia between Caucasian and Afro-American populations. Because of the higher frequency of hypertension and stroke in Afro-Americans, an increased proportion of the vascular and the mixed Alzheimer and vascular type of demen$\mathrm{tia}^{22}$ would be expected. In the absence of biological markers and unequivocal clinical or morphological criteria, cross cultural comparisons of the risk of subtypes of dementia will be difficult to interpret.

\section{Time trends}

Variation in incidence of dementia over time within a population may lead to hypotheses about environmental risk factors. Again, studies of the prevalence of dementia are less informative for this as they may be biased by differences in survival. Despite the lack of specific treatment, survival of patients may have improved. ${ }^{52324}$ There are only two long term follow up studies available which have monitored incidence of dementia over time. Data on the incidence of senile dementia over a 25 year period (1947-72) are available from a study conducted in Lundby, Sweden. ${ }^{5}$ In this study, there was no evidence for a trend over time. Data on incidence collected in Rochester, Minnesota in the period 1960-84 suggested that changes in incidence of dementia may have occurred. ${ }^{11} \mathrm{~A}$ higher incidence of dementia was found in the earliest (1960-4) as well as the latest (1980-4) period studied and was found to be limited to the very old. However, the increased awareness of dementing illness in the past decade may have influenced rates of diagnosis in the later period. ${ }^{11}$ So far, studies of trends in the incidence of dementia over time have yielded few clues about the aetiology of the disease.

\section{Clinical characteristics}

Clinical epidemiological studies in patients with heterogeneous disorders, such as 
Alzheimer's disease and other subtypes of dementia, may lead to advances in the understanding of the pathophysiology and open new leads to interventions that slow the progression of disease. Further, subtyping of dementias according to aetiology is important in establishing prognosis as well as for selection of homogeneous case series for clinical trials. The existence of subgroups may be explored by studies on clinical and pathological characteristics and survival of patients. Here, the characteristics of the two most common subtypes of dementia, Alzheimer's disease and vascular dementia, are discussed.

\section{ALZHEIMER'S DISEASE}

Neuropathological features of Alzheimer's disease comprise neuritic plaques, amyloid angiopathy, neuronal loss, and neurofibrillary tangles. Amyloid fibrils composed of the amyloid protein (A4 protein) make up the core of the neuritic plaques. Neurofibrillary tangles consist of intraneuronal paired helical filaments, which are in part composed of altered forms of the microtubule associated protein tau. Although clinically Alzheimer's disease is a diagnosis by exclusion of other causes of dementia, ${ }^{18} 19$ the disease is characterised by an impaired learning ability, a decline in language function, and deterioration of visuospatial skills. $^{25}$ Calculation, abstraction, and judgement are often affected, the onset of the disease is insidious, and in the early stages, changes in personality are common. ${ }^{18} 1925$

Although the origin of the disease is unknown in most patients, there are known gene mutations that may cause an early onset form of Alzheimer's disease. Mutations in the $\beta$ amyloid precursor protein (APP) gene on chromosome 21 have been found in a few families, which cause an autosomal dominant form of early onset Alzheimer's disease (onset $<55$ years). ${ }^{26}$ Recently, two homologous genes-presenilin 1 (PS-1) on chromosomes 14 and presenilin 2 (PS-2) on chromosome 1 -have been identified that lead to familial autosomal dominant forms of early onset Alzheimer's disease (onset age between 30-55 years and 50-70 years respectively)..$^{27-29}$ The $\varepsilon 4$ allele of the apolipoprotein $\mathrm{E}$ gene on chromosome 19 (APOE ${ }^{\star} 4$ ) has been shown to be associated with an increased risk for late onset $^{30} 31$ as well as early onset Alzheimer's disease. $^{32} 33$

Patients with dementia have a reduced life expectancy compared with the general population and other institutionalised patients. ${ }^{23} 243435$ Among patients with Alzheimer's disease, there are major differences in mortality. ${ }^{34}$ The wide range in survival may in part be explained by differences in duration of disease at entry into the study. A meta-analysis of community, clinic, and nursing home based studies on survival showed mortality to be increased in men. ${ }^{34}$ However, studies of prevalent cases may be biased as patients who die early in the course of disease are less likely to be included in the study, resulting in an overestimation of survival. Survival in incident cases has been considered in four community based studies. ${ }^{46824}$ Survival was significantly worse in male patients with Alzheimer's disease in a study in Rochester, ${ }^{24}$ but not in others. ${ }^{46}$ However, the small sample size hampers the interpretation of the latter studies. Findings in the Rochester study suggest that five year survival (period 1975-84) decreases with age of onset of disease from $84 \%$ in patients with an onset at or before 69 years to $81 \%$ in patients with an onset between 70 and 79 years and to $40 \%$ in patients with an onset after 80 years. ${ }^{24}$ However, the reduced survival in elderly patients may be a consequence of the reduced life expectancy in the late onset patients. After adjusting for the higher life expectancy in younger patients, a study conducted in New York (the Bronx), suggested that the risk of mortality increased with decreasing age of onset of disease. ${ }^{6}$ This finding suggests that an earlier onset of disease may be more malignant.

Alzheimer's disease is often accompanied by the development of extrapyramidal symptoms, myoclonus, psychosis, seizures, aphasia, and primitive reflexes. ${ }^{36-39}$ Several studies have shown that patients developing one of these symptoms tend to deteriorate to specific cognitive and functional end points more rapidly than those without these symptoms. ${ }^{36-40}$ It is not clear at present whether these symptoms reflect a clinical subgroup of patients with Alzheimer's disease or whether they are merely markers of disease progression. The finding of an increasing frequency of these symptoms during the course of disease is compatible with the view that these factors are markers of disease progression. ${ }^{36}$ On the other hand, the frequency of myoclonus and aphasia early in the course of disease is increased in patients of families in which Alzheimer's disease is linked to a mutation on chromosome $14 .^{11-43}$ This suggests that these clinical features reflect different aetiology. The ongoing dissection of Alzheimer's disease by its genetic causes may yield important information on the origin and relevance of concomitant pathology in Alzheimer's disease.

Little is known of the relation between genetic factors and mortality in patients with Alzheimer's disease. The number of patients with dominant mutations is small, which complicates studies on the relation of these mutations to survival. However, it has been shown that patients of families in which Alzheimer's disease is inherited as an autosomal dominant disorder have, in general, a worse progression. ${ }^{44}$ Findings on APOE ${ }^{\star} 4$ have been controversial. One study reported no association between survival and clinical characteristics, ${ }^{45}$ whereas other studies suggest that $\mathrm{APOE}^{\star} 4$ is associated with a slower progression and prolonged survival in patients with Alzheimer's disease. ${ }^{46-48}$ The $\varepsilon 2$ allele of apolipoprotein $\mathrm{E}$ $\left(\mathrm{APOE}^{\star} 2\right)$ has been associated with an increased mortality in one study, ${ }^{48}$ but this finding remains to be confirmed.

\section{VASCULAR DEMENTIA}

Vascular dementia is a syndrome that may be caused by several vascular lesions, including 
ischaemic, hypoxic, and haemorrhagic brain damage. ${ }^{25}$ The clinical diagnosis requires the presence of (a) dementia, (b) cerebrovascular disease evidenced by neuroimaging and by neurological symptoms, and (c) a temporal relation between the vascular disease and dementia. ${ }^{25}$ Vessel occlusion seems to be the most common pathology underling vascular dementia. ${ }^{25}$

Several clinical subtypes of vascular dementia have been recognised, including multiinfarct dementia, lacunar state, and Binswanger's disease. ${ }^{25}$ Diagnosis of these subtypes of vascular dementia syndromes has been facilitated by the progress in neuroimaging. ${ }^{49}$ Clinical-epidemiological studies with MRI are likely to play an important part in separating clinically and aetiologically relevant subgroups, especially in combination with genetic studies. Thus far, genetic and MRI studies have been successful in unravelling the aetiology of cerebral autosomal dominant arteriopathy with subcortical infarcts and leukoencephalopathy (CADASIL). ${ }^{5051}$ This is an inherited disease associated with dementia, stroke and transient ischaemic attacks, migraine with aura, and mood disorders. ${ }^{50} 51$ Abnormalities on MRI are found in the subcortical white matter and basal ganglia and can be detected before the clinical expression of the disease. ${ }^{5051}$ Molecular research suggests that CADASIL is linked to a gene on chromosome $19 .{ }^{50}$

Studies on the survival of patients have consistently shown a reduced life expectancy for patients with vascular dementia compared with the general population. Survival is worse than in patients with Alzheimer's disease. ${ }^{21} 23343539$ The number of studies on predictors of survival for vascular dementia is still small, but male sex, ${ }^{39} 52$ low education, ${ }^{52}$ advanced disability, ${ }^{39}$ and primitive reflexes ${ }^{39}$ have been associated with poorer prognosis.

\section{Risk factors}

Most studies of risk factors for dementia have focused on the commonest subtype, Alzheimer's disease. Studies conducted before 1991 have been reviewed and collaboratively reanalysed by the EURODEM Risk Factors Research Group. ${ }^{53-60}$ Here, the findings of more recent studies will be evaluated in the light of this reanalysis. However, it is important to realise that most studies were based on the comparison of prevalent cases of Alzheimer's disease with control subjects. ${ }^{53}$ Such studies are prone to various types of bias. Selection bias may have occurred due to mortality in patients related to the risk factor studied. Assessment of exposure to the risk factor has often been based on information from surrogates, which may introduce error. Further, differential misclassification in exposure to risk factors between cases and controls may have occurred, as informants of patients may have been better at recalling exposures than controls. The relation of most risk factors for Alzheimer's disease remains to be confirmed in follow up studies of incident patients, in which the exposure state is measured before the onset of disease.

\section{AGE AND SEX}

The risk of dementia and Alzheimer's disease increases strongly with age (see figs 1 and 2),,$^{1-3}$ suggesting that genetic and environmental factors which influence aging of the brain may play an important part. Two studies of the incidence of Alzheimer's disease found that the disease occurred more often in women than men, ${ }^{517}$ but most studies show a similar incidence in men and women. ${ }^{491114}$ Vascular dementia has been found to be more frequent in men than women, ${ }^{41417}$ which probably reflects the higher frequency of vascular disease in men. The incidence of vascular dementia in men and women increased with age in the long term follow up study conducted in Lundby. ${ }^{5}$ By contrast, an increase in incidence of vascular dementia with age was found only in women in the study conducted in the Bordeaux area in France. ${ }^{14}$ However, the number of patients studied was small.

\section{GENETIC RISK FACTORS}

Alzheimer's disease aggregates within families of patients with early and late onset of disease. ${ }^{54}$ Several genes (APP, PS-1, PS-2) have been identified that are involved in the autosomal dominant forms of early onset Alzheimer's disease. ${ }^{26-29}$ However, the role of these genes in late onset Alzheimer's disease, which concerns the vast majority of patients in the population, is limited. In the patients with late onset disease, the APOE gene on chromosome 19 seems to play a part. ${ }^{30-32}$ Other forms of dementia including vascular dementia, ${ }^{61}{ }_{62}$ Lewy body disease, ${ }^{63}$ and Creutzfeldt-Jakob disease $^{64}$ have also been associated with $\mathrm{APOE}^{\star} 4$. Further, $\mathrm{APOE}^{\star} 4$ has been associated with decreased cognitive function and increased rates of cognitive decline in the general population. . $^{65-68}$

Despite the fact that many studies have consistently shown an increased risk of Alzheimer's disease for $\mathrm{APOE}^{\star} 4$ carriers, ${ }^{69}$ some questions remain to be clarified to identify clinically relevant risk groups. There is still controversy about whether the risk associated with the APOE ${ }^{\star} 4$ allele may be modified by sex, ${ }^{70-72}$ ethnicity, ${ }^{73-75}$ age, ${ }^{72}{ }^{76}$ or family history of dementia. ${ }^{337277}$ Although findings of two studies are compatible with modification of the risk of Alzheimer's disease for APOE ${ }^{\star} 4$ carriers by sex, ${ }^{7072}$ one study failed to show evidence for interaction. ${ }^{71}$ Among African and Afro-American populations, the risk associated with $\mathrm{APOE}^{\star} 4$ is unclear as a lack of association between $\mathrm{APOE}^{\star} 4$ and the risk of Alzheimer's disease has been found in some studies ${ }^{7375}$ but not in others. ${ }^{74}$ Several studies found the relation between $\mathrm{APOE}^{\star} 4$ and Alzheimer's disease to be absent in the very elderly patients. ${ }^{7678}$ Some studies have suggested that the strongest effect of $\mathrm{APOE}^{\star} 4$ occurs in those with a positive family history. ${ }^{3377} \mathrm{~A}$ meta-analysis on the modification of the strength of association between $\mathrm{APOE}^{\star} 4$ and the risk of Alzheimer's disease 
by age and family history of dementia showed that the $\mathrm{APOE}^{\star} 4$ allele frequency was highest among patients with familial Alzheimer's disease, the APOE ${ }^{\star} 4$ frequency being 0.48 (95\% confidence interval (95\% CI): $0.45-0.51)$ in those with late onset and $0.42(95 \% \mathrm{CI}$ : $0.36-0.48)$ in those with early onset of disease. ${ }^{69}$ The APOE ${ }^{\star} 4$ allele frequency was significantly higher in patients with late onset sporadic Alzheimer's disease (APOE $\star 4$ frequency: $0.37 ; 95 \% \mathrm{CI}: 0.35-0.39$ ) than in patients with early onset sporadic disease (APOE ${ }^{\star} 4$ frequency: $0.28 ; \quad 95 \% \quad \mathrm{CI}$ : $0 \cdot 23-0.33) .{ }^{69}$ This finding suggests that the risk of disease may be modified by age in patients with sporadic Alzheimer's disease.

Another issue that remains to be resolved is the association of Alzheimer's disease with the APOE ${ }^{\star} 2$ allele. Several studies noted a lower frequency of the $\mathrm{APOE}^{\star} 2$ allele in patients with Alzheimer's disease, suggesting that there may be a protective effect of $\mathrm{APOE}^{\star} 2 .{ }^{3279}$ However, an increased risk for carriers of APOE $^{\star} 2$ was found in an Italian, ${ }^{80}$ a Dutch, ${ }^{48}$ and an Afro-American population. ${ }^{74}$ There are several possible explanations for the differences in association between Alzheimer's disease and $\mathrm{APOE}^{\star} 2$ across populations, including linkage disequilibrium with another gene and modification by other genetic and environmental factors. ${ }^{48}$ The discrepancies may also be a result of the reduced survival of patients with $\mathrm{APOE}^{\star} 2 .{ }^{48}$ As most studies were based on prevalent cases, APOE ${ }^{\star} 2$ carriers may have been selectively removed from the patient series over time. This may have resulted in an apparent decrease of the $\mathrm{APOE}^{\star} 2$ allele frequency. In a similar way, the increased survival for patients with Alzheimer's disease with $\mathrm{APOE}^{\star} 4$ that has been found in some studies may have led to an overrepresentation of $\mathrm{APOE}^{\star} 4$ carriers in patients with Alzheimer's disease. ${ }^{46-48}$ Although it is unlikely that the relation between $\mathrm{APOE}^{\star} 4$ and Alzheimer's disease can be explained fully by survival effects, reduced mortality in $\mathrm{APOE}^{\star} 4$ carriers may have led to an overestimation of the risk of Alzheimer's disease associated with the $\mathrm{APOE}^{\star} 4$ allele. ${ }^{48}$

The mechanism through which APOE affects the risk of Alzheimer's disease and other types of dementia remains to be elucidated. The $\mathrm{APOE}^{\star} 4$ allele has been implicated in various aspects of Alzheimer's disease pathology including $\beta$ A4 amyloid deposition in senile plaques as well as in microtubule instability and paired helical filament formation. ${ }^{3081} \mathrm{APOE}^{\star} 4$ has also been shown to increase the risk of atherosclerosis, which may explain its association with vascular dementia.

\section{DOWN'S SYNDROME}

The increased risk of Alzheimer's disease in people with Down's syndrome has long been recognised. Alzheimer pathology has been found in most elderly patients with Down's syndrome. ${ }^{82}$ When pooling and reanalysing the early case-control studies, there was considerable evidence for familial aggregation of
Down's syndrome and both early and late onset Alzheimer's disease, ${ }^{54}$ but recent studies of patients with Alzheimer's disease have failed to show a significant association. ${ }^{83-89}$ However, the negative findings may be a result of the low statistical power of individual studies.

As the frequency of Alzheimer's disease in the population is considerably higher than the frequency of Down's syndrome, studies of family history of dementia in patients with Down's syndrome have a higher statistical power. Although the early studies on family history did not yield consistent results, ${ }^{9091}$ a recent study has shed new light on this issue..$^{92}$ The study showed an increased risk of dementia in mothers of patients with Down's syndrome, but not in fathers, suggesting that non-dysjunction of chromosomes in the mother may play a part in familial aggregation of Down's syndrome and Alzheimer's disease. ${ }^{92}$ The risk of dementia in mothers was increased only when the mother was younger than 35 years old at the birth of the child with Down's syndrome.92 This finding suggests that the association is not explained by an increased risk of non-dysjunction with advanced maternal age but that other factors are involved. Because familial aggregation of Down's syndrome and Alzheimer's disease has been found to be strongest in those with a positive family history, it is possible that genetic factors may be implicated. ${ }^{93}$

PARKINSON'S DISEASE AND LEWY BODY DISEASE Alzheimer's disease, Parkinson's disease, and Lewy body disease share several pathological features. The Lewy body and Alzheimer pathology can be found in each of these disorders. Dementia, a cardinal feature of Alzheimer's disease and Lewy body dementia, is often found in patients with Parkinson's disease. ${ }^{25} 94$ There is some evidence for a common genetic origin of these disorders. Early studies were compatible with familial aggregation of Alzheimer's disease and Parkinson's disease, ${ }^{54}$ being strongest in the families of patients with a positive family history of dementia. ${ }^{93}$ Although more recent studies failed to confirm familial aggregation of these disorders, ${ }^{83-858889}$ the results of molecular genetic research suggest that they may have a common genetic origin. An increased risk of both Alzheimer's disease and Lewy body dementia has been associated with the APOE gene..$^{30-3363}$ In recent studies, CYP2D6B, a gene that has been associated with Parkinson's disease and Lewy body disease, has also been associated with the Lewy variant of Alzheimer's disease and with synaptic pathology in Alzheimer's disease. ${ }^{9596} \mathrm{It}$ is not yet clear whether any of these findings may explain familial aggregation of these disorders.

\section{MATERNAL AGE AT BIRTH}

As a corollary of the findings on Down's syndrome and family history of Down's syndrome, parental age has been studied as a potential risk factor for Alzheimer's disease. The findings are inconsistent. Some studies have suggested an association with late maternal age, 558588 some found a significant increase 
in risk for young maternal ${ }^{55} 97$ and young paternal age, ${ }^{86} 97$ and some found no evidence for an association at all. ${ }^{55} 89$ Although young parental age has been associated with a moderate increase in risk of Down's syndrome, it seems unlikely that the strong association of Alzheimer's disease with young maternal and paternal age can be explained by an increase in risk of chromosome 21 non-dysjunction in meiosis at an early age. ${ }^{55}$

\section{HEAD TRAUMA}

Repeated head trauma in boxers has been associated with dementia pugilistica. The similarity in pathology of dementia pugilistica to the Alzheimer pathology has led to the hypothesis of a common pathogenesis of Alzheimer's disease and dementia. Early epidemiological studies were remarkably consistent in showing that patients were more often exposed to head trauma in the past than were controls, although the differences were not always significant..$^{56}$ Of the recent studies, three reported a significant increased risk of Alzheimer's disease after head trauma, ${ }^{89} 9899$ and four did not. ${ }^{83-8588}$ Studies of the history of head trauma have all been hampered by recall bias. Relatives of patients may have been more likely to remember head injuries that occurred in the past than relatives of controls. One prospective follow up study based on data obtained from the Rochester medical records showed only a slight and non-significant increase in risk. ${ }^{56}$ However, a recent study suggests that the association may be modified by the presence of the $\mathrm{APOE}^{\star} 4$ allele. ${ }^{100}$ An increased risk of Alzheimer's disease after head trauma was only found in carriers of the $\mathrm{APOE}^{\star} 4$ allele. ${ }^{100}$ Any bias in recalling head trauma would be expected to be independent of APOE genotype and this finding, if confirmed, lends strong support to a relation between head trauma and Alzheimer's disease in the subgroup of cases who are $\mathrm{APOE}^{\star} 4$ carriers. Regarding the biological mechanism, recent experimental studies suggested that the expression of $\beta$ amyloid and interleukin 1 are increased after head trauma and that head trauma may be related to Alzheimer's disease through the induction of an acute phase response. ${ }^{101}$

\section{DEPRESSION}

Early studies suggested that a history of depression may be a risk factor for Alzheimer's disease. ${ }^{58}$ The risk of Alzheimer's disease increased for those treated for depression 10 years or more before the first symptoms of dementia, suggesting that the depression was not simply a consequence of the dementia. ${ }^{58} \mathrm{~A}$ similar association was present in a follow up study, in which the history of depression before the onset of disease was assessed from medical records. ${ }^{58}$ Two recent studies showed no relation between depression and Alzheimer's disease, ${ }^{83}{ }^{89}$ but another reported a non-significant increase in risk of Alzheimer's disease in subjects with a history of depression in the previous three years. ${ }^{86}$ Familial aggregation of depression has been reported in patients with Alzheimer's disease and a positive family history of dementia. ${ }^{102}$ This suggests that genetic factors may underlie the relation. ${ }^{102}$ However, it remains to be excluded that depression is merely an early sign of Alzheimer pathology.

\section{THYROID DISEASE}

There is some evidence from the early studies of risk factors for Alzheimer's disease for an increased risk of disease in patients with hypothyroidism. ${ }^{57}$ Further, an association between Alzheimer's disease and autoimmune thyroid disease has been reported in Down's syndrome and familial Alzheimer's disease. ${ }^{103104}$ None of the recent studies has confirmed the association with thyroid disease. ${ }^{8388} 89$ However, these studies were based on data from informants. One study on the history of thyroid disease based on medical records suggested that the risk of Alzheimer's disease was decreased for patients with Graves' disease, whereas there was a nonsignificant increase in risk for patients with myxoedema. ${ }^{105}$ These findings and their pathophysiological importance remain to be clarified.

\section{VASCULAR FACTORS}

In recent years, the interest in vascular causes of dementia has increased, partly because there may be opportunities for prevention and treatment for this type of dementia. By definition, vascular disease and its risk factors must be present in patients with vascular dementia. ${ }^{25}$ Factors that have been implicated in the risk of vascular dementia include hypertension, diabetes mellitus, and cardiovascular disease. ${ }^{106}$ The mechanism through which these factors lead to dementia is unclear. Vascular factors may also be involved in Alzheimer's disease. ${ }^{106}$ However, their role is difficult to quantify as patients with vascular disease are less likely to be diagnosed as cases of Alzheimer's disease. ${ }^{1819}$ White matter lesions have been found in increased frequency in patients with Alzheimer's disease in some studies but not in others. ${ }^{107} 108$ Although these lesions have been associated with atherosclerosis, ${ }^{109}$ they are not specific and may reflect cerebral atrophy and amyloid angiopathy in patients with Alzheimer's disease. ${ }^{107} 108$ There is evidence from one MRI study that suggests that arteriolosclerosis may be specific for patients with late onset Alzheimer's disease. ${ }^{108}$

\section{ANTI-INFLAMMATORY DRUGS}

From experimental studies, there is increasing evidence that acute and chronic inflammatory processes play an important part in the pathophysiology of Alzheimer's disease. ${ }^{110111}$ Novel findings that may have clinical relevance are the inverse relations between Alzheimer's disease and past use of anti-inflammatory drugs and with rheumatoid arthritis, a disorder for which these drugs are often prescribed. $.^{84} 89112-114$ As the only follow up study failed to show a relation between rheumatoid arthritis and Alzheimer's disease, ${ }^{115}$ a possible protective effect of anti-inflammatory drugs remains to 
be clarified. Preliminary evidence showing that cognitive decline may be less in subjects taking indomethacin than in control subjects, indicates that further studies may be of interest. ${ }^{116}$

\section{OESTROGEN REPLACEMENT THERAPY}

Oestrogen may be implicated in Alzheimer's disease in several ways. Improvement of cerebral blood flow, direct stimulation of neurons, development of gliacytes, and suppression of apolipoprotein $\mathrm{E}$ have been suggested. ${ }^{117}$ However, findings of epidemiological studies have been controversial. One study, based on computerised pharmaceutical records, did not show evidence for a relation, ${ }^{118}$ whereas two studies based on anamnestic data suggested a protective effect of oestrogen replacement therapy. ${ }^{119120}$ There are important methodological problems which make the interpretation of the latter studies difficult. In one, a follow up study, based on direct interviews before onset of disease, the diagnosis of Alzheimer's disease at follow up depended on mortality records. ${ }^{119}$ Mortality records have been shown to be unreliable for the ascertainment of patients with Alzheimer's disease. In the other study, the history of oestrogen use was obtained from informants for cases of Alzheimer's disease but from the control women directly. ${ }^{120}$ Lack of knowledge of the use of oestrogens by the informant may explain part of the inverse relation found. Although some experimental studies on oestrogen suggest a beneficial effect, ${ }^{117}$ there is no convincing evidence from epidemiological studies confirming such a role of oestrogen in Alzheimer's disease.

\section{SMOKING HISTORY}

Early epidemiological studies suggested an inverse association between Alzheimer's disease and history of smoking, ${ }^{59}$ but recent studies have yielded equivocal results. The association between smoking and Alzheimer's disease was found to be absent in three studies, ${ }^{88} 89121$ inverse in two, ${ }^{122} 123$ and positive in one. ${ }^{86}$ The inverse association seemed to be related to social class in one study. ${ }^{123}$ The results of a recent meta-analysis were compatible with a decreased risk of Alzheimer's disease in smokers. ${ }^{124}$ There is some evidence that genetic factors, including the APOE gene, may alter the association between smoking and Alzheimer's disease. ${ }^{93125}$ The inverse relation between smoking and Alzheimer's disease was found to be limited to those with the $\mathrm{APOE}^{\star} 4$ allele that had a positive family history..$^{93} 125$ However, modification of the relation between smoking and Alzheimer's disease by APOE has not been confirmed in other studies. ${ }^{126}$

Experimental studies of rats and rabbits have suggested that nicotine may improve memory and cognition. ${ }^{127}$ Moreover, blockade of nicotinic receptor function may produce a significant cognitive impairment in humans ${ }^{128}$ and clinical trials have suggested that nicotine and nicotine derivatives may improve information processing and attention in patients with Alzheimer's disease. ${ }^{129130}$ However, there was no evidence for improvements in memory or cognition. ${ }^{129130}$ This suggests that nicotine or its derivates modifies a rather limited spectrum of the clinical course of the disease.

Most studies of Parkinson's disease have also reported an inverse association with smoking. ${ }^{131}$ By contrast with the findings on Alzheimer's disease and Parkinson's disease, the risk of vascular dementia was found to be increased for subjects that smoked, ${ }^{106}$ suggesting a different effect of smoking in these disorders, rather than a general mechanism between smoking and dementia.

\section{ALCOHOL}

There was no evidence for an increase in risk of Alzheimer's disease in people with a moderate alcohol intake in a reanalysis of early casecontrol studies of Alzheimer's disease. ${ }^{59}$ Also, no relation was found between alcohol consumption and Alzheimer's disease in two recent studies including one follow up study. ${ }^{89} 122$ These findings should be treated with caution. Cases with higher alcohol intake may have been excluded when applying the criteria for probable or possible Alzheimer's disease, ${ }^{1819}$ leading to an underestimation in risk. Indeed, alcohol misuse has been associated with a significant increased risk of dementia $^{132}$ and Alzheimer's disease ${ }^{85}$ in two population based studies.

\section{OCCUPATIONAL EXPOSURE}

Findings on occupational exposure to solvents have been controversial. No significant increased risk for occupational exposure to solvents and lead was found when pooling the early studies. ${ }^{60}$ However, in the pooled analysis frequency of exposure was low and exposure definition was imprecise. ${ }^{60}$ Two recent casecontrol studies have reported an association with occupational exposures. ${ }^{89} 133$ In one study, an increased risk of Alzheimer's disease was found for subjects exposed to glues and pesticides ${ }^{89}$ Another study suggested a statistically significant increase in risk of Alzheimer's disease for men exposed to solvents such as benzene, toluene, phenols, alcohols, and ketones. ${ }^{133}$ Studies on subjects exposed occupationally to solvents have suggested that risk of neurological symptoms may be modified by heavy alcohol consumption. ${ }^{134}$ Whether the increased risk for Alzheimer's disease depends on the alcohol consumption or some other occupational exposure is not known at present.

\section{ALUMINUM}

There has been extensive debate on the question whether aluminum is implicated in the aetiology of Alzheimer's disease. The initial epidemiological studies were instigated in response to the finding of aluminum in neuritic plaques and tangle-bearing neurons. However, more recent studies of the association between aluminum and the Alzheimer pathology have yielded contradicting results. ${ }^{135}$ On the other hand, there is growing evidence from experimental studies that aluminum may influence the conformation of both amyloid and neurofibrillary tangles. ${ }^{136-138}$ 
Follow up studies of the presence of Alzheimer pathology in the brains of patients who were on dialysis and exposed to high doses of aluminum have not been conclusive. ${ }^{139} 140$ Epidemiological studies on the association between aluminum in drinking water and the risk of Alzheimer's disease have been reviewed recently. ${ }^{141}$ With the exception of one study, ${ }^{88}$ findings have been consistent in suggesting an increased risk of Alzheimer's disease with increasing aluminum concentration in drinking water. ${ }^{141142}$ However, the possibility of bias in present studies still outweighs the evidence for causal inference. ${ }^{141}$ Studies that have considered the role of aluminum products such as antacids and antiperspirants have yielded equivocal results. ${ }^{84} 89$ Supporting a role of aluminum in Alzheimer's disease was the finding of a lower level of cognitive functioning among miners treated with aluminum powder ${ }^{143}$ and the finding of a slower progression of the disease in patients with Alzheimer's disease treated with aluminum chelating drugs. ${ }^{144}$

Despite the strong evidence from experimental studies that aluminum may be implicated in the Alzheimer pathology and progression of the disease, there are many questions to be answered from an epidemiological point of view. An issue that complicates the interpretation of the negative studies is the possibility that the effect of aluminum may depend on an interaction with other environmental factors. For instance, the risk of Alzheimer's disease associated with aluminum in drinking water may be influenced by the $\mathrm{pH}^{142}$ or the presence of silicon. ${ }^{145}$ Aluminum concentrations in serum and bone from cases of Alzheimer's disease are not raised suggesting that aluminum exposure and absorption is similar in patients with Alzheimer's disease and controls. ${ }^{146} 147$ However, it is conceivable that genetic factors ${ }^{148}$ or other (patho)physiological factors (for example, head trauma) may enable aluminum to enter the brain. Thus the increase in risk of Alzheimer's disease associated with aluminum may be present only in a subgroup of patients. These are issues that can only be considered in large scale epidemiological studies.

\section{EDUCATION}

It has been suggested that highly educated subjects have a lower risk of Alzheimer's disease and other types of dementia. ${ }^{149}$ However, this finding was based on prevalent cases. ${ }^{149}$ Two community based studies of incident cases failed to show an association of education with risk of Alzheimer's disease, suggesting that survival and selection bias may explain the earlier results. ${ }^{150} 151$ Recent studies have produced conflicting results. Higher educational attainment was associated with an increased mortality ${ }^{152}$ but a less severe stage of disease at the time of presentation in patients with Alzheimer's disease. ${ }^{153}$ A relation between risk of vascular dementia and lower education levels was also found in a study of incident cases. ${ }^{151}$ This finding may be explained by the relation between low socioeconomic class and vascular disease.

\section{Discussion}

By contrast with epidemiological studies of other chronic disorders, cross cultural studies have not led to important clues to the aetiology of dementia or any of its subtypes. There may be differences in the risk of vascular dementia between populations, but comparative studies of geographical and time trends are difficult to interpret because of the lack of biological markers and unique clinical features for the subtypes of dementia. Cross cultural comparison of studies of Alzheimer's disease showed no evidence for the existence of risk factors that are to be found predominantly in some populations but not in others. The risk factors for Alzheimer's disease seem to be ubiquitous.

Aetiological studies have uncovered some putative risk factors for Alzheimer's disease. There is growing evidence that several disorders including Down's syndrome, Parkinson's disease, depression, head injury, and perhaps thyroid disease may be associated with an increase in the risk of Alzheimer's disease. Familial aggregation of Alzheimer's disease with Down's syndrome, depression, and perhaps Parkinson's disease suggests that there may be a common genetic factor underlying these disorders in at least a subgroup of patients. As to environmental factors, the influence of alcohol and smoking is still controversial. Given the widespread exposure to aluminum through food products and drinking water, the relation between aluminum and Alzheimer's disease deserves further attention.

Epidemiological research on Alzheimer's disease is far from its limits. Most studies of risk factors for this disease have been small, whereas risk factors were rare. ${ }^{53}$ The validity of studies has been compromised by anamnestic data collected through surrogate informants. Long term follow up studies, that are currently ongoing, will overcome these problems. Nonresponse, competing mortality, and comorbidity complicating the diagnosis, in particular in elderly people, will be challenges to overcome in these studies. However, advances in epidemiological research will not depend only on improved methodology. Recent epidemiological studies have led to preliminary findings of a protective effect of anti-inflammatory drugs and perhaps oestrogen replacement therapy that may prove to be of clinical relevance. Progress in the understanding of the genetics of Alzheimer's disease and other types of dementia has opened new possibilities for epidemiological studies on the risk associated with these genetic factors. Firstly, the risk of Alzheimer's disease associated with the various genetic factors identified including APOE remains to be quantified in follow up studies of incident cases. Secondly, the possibility of interaction between genetic and environmental risk factors needs to be studied, as the strength of association between an environmental factor and the risk of disease may 
depend on the presence of a genetic factor. ${ }^{93}$ Conversely, the effect of the genetic factor on the risk of Alzheimer's disease may be conditional on the presence of other genetic and environmental risk factors. ${ }^{93}$ For APOE, there is some evidence for synergistic effects of $\mathrm{APOE}^{\star} 4$, head trauma, and cholesterol and antagonistic effects of $\mathrm{APOE}^{\star} 4$ and smoking with regard to the risk of Alzheimer's disease. ${ }^{72} 100125$ Interaction of APOE with other possible risk factors including vascular factors needs to be studied further. As pathological and molecular biological research proceeds, Alzheimer's disease and other types of dementia are likely to be dissected further into aetiologically relevant subgroups.

CMvD is supported by grants of the Netherlands Organization for Scientific Research (NWO) and the Netherlands Institute for Health Sciences (NIHES). ACJW Janssens and AJC Slooter are acknowledged for helpful discussions of the manuscript.

1 Hofman A, Rocca WA, Brayne C, et al. The prevalence of dementia in Europe: a collaborative study of 1980-1990 findings. Int $\mathcal{F}$ Epidemiol 1991;20:381-90.

2 Rocca WA, Hofman A, Brayne C, et al. Frequency and distribution of Alzheimer's disease in Europe: a collaborative study of 1980-1990 findings. Ann Neurol 1991;381:381-90

3 Breteler MMB, Claus JJ, van Duijn CM, et al. Epidemiology of Alzheimer's disease. Epidemiol Rev 1992; 14:59-82.

4 Nilsson LV. Incidence of severe dementia in an urban sam ple followed from 70-79 years of age. Acta Psychiatr Scand 1984;70:478-86.

5 Rorsman B, Hagnell O, Lanke J. Prevalence and incidence of senile and multi-infarct dementia in the Lundby study: a comparison of the time periods 1947-1957 and 1957-1972. Neuropsychobiology 1986; 15:122-9.

6 Aronson MK, Ooi WL, Geva DL. Dementia. Age-dependent incidence, prevalence and mortality in the old old. Arch Intern Med 1991;151:989-92.

$7 \mathrm{Li} \mathrm{G}$, Shen YC, Chen $\mathrm{CH}$, et al. A three-year follow-up study of age-related dementia in an urban area of study of age-related dementia in an urban

8 Copeland JRM, Davidson IA, Dewey ME, et al. Alzheimer's disease, other dementia, depression and pseudo-dementia: prevalence, incidence and three-year outcome in Liverpool. Br f Psychiatry 1992;161:230-9.

9 Bachman DL, Wolf PA, Linn RT, et al. Incidence of dementia and Alzheimer's disease in a general population: the Framingham Study. Neurology 1993;43:515-9.

10 Morgan K, Lilley JM, Arie T, et al. Incidence of dementia in a representative British sample. Br F Psychiatry 1993; 163:467-70.

11 Kokmen E, Beard CM, O'Brien PC, et al. Is the incidence of dementing illnes changing? A 25-year time trend study in Rochester, Minnesota (1960-1984). Neurology 1993;43:1887-92.

12 Boothby H, Blizard R, Livingston G, Mann AH. The Gospel Oak Study stage III: the incidence of dementia. Psychobiol Med 1994;24:89-95.

13 Bickle $\mathrm{H}$, Cooper B. Incidence and relative risk of dementia in an urban elderly population. Findings of a prospective field study. Psychobiol Med 1994;24:179-92.

14 Letenneur L, Commenges RD, Dartigues JF, SabergerGateau P. Incidence of dementia and Alzheimer's disease in elderly community residents of south-western France. Int $\mathcal{F}$ Epidemiol 1994;23:1256-61.

15 Paykel ES, Brayne C, Huppert F, et al. Incidence of dementia in a population older than 75 years in the United Kingdom. Arch Gen Psychiatry 1994;51:325-32.

16 Hebert LE, Scherr PA, Beckett LA, et al. Age-specific incidence of Alzheimer's disease in a community populaincidence of Alzheimer's disease

17 Yoshitake T, Kiyohara Y, Kato I, et al. Incidence and risk factors of vascular dementia and Alzheimer's disease in a defined elderly Japanese population. The Hisayama study. Neurology 1995;45:1161-8.

18 American Psychiatric Association. Diagnostic and statistical manual of mental disorders. 3rd ed revised. 1980 .

19 McKhann G, Drachman D, Folstein M, et al. Clinical diagnosis of Alzheimer's disease: report of the NINCDS-ADRDA Work Group under the auspices of Department of Health and Human Services Task Force on Alzheimer's disease. Neurology 1984;34:39-44.

20 Jorm AF. Cross-national comparison of the occurrence of Alzheimer's disease and vascular dementia. Eur Arch Psychiatry Clin Neurosci 1991;240:218-22.

21 Skoog I, Nilsson L, Palmertz B, et al. A population-based study of dementia in 85-year-olds. $N$ Engl $\mathrm{f} \mathrm{Med}$ 1993;328:153-8.
22 Heyman A, Fillenbaum G, Prosnitz B, et al. Estimated prevalence of dementia among elderly black and white community residents. Arch Neurol 1991;48:594-8.

23 Rorsman B, Hagnell O, Lanke J. Prevalence of age psychosis and mortality among aged psychotics in the Lundby study. Neuropsychology 1985;13:167-72

24 Beard CM, Kokmen E, O'Brien PC, Kurland LT. Are patients with Alzheimer's disease surviving longer in recent years? Neurology 1994;44:1869-71.

25 Cumlings CL. The failing brain. Lancet 1995;345:1481-9.

26 Goate A, Chartier-Harlin M-C, Mullan M, et al. Seggregation of a missense mutation in the amyloid precursor protein gene with familial Alzheimer's disease. cursor protein gene with

27 Sherrington R, Rogaev EI, Liang Y, et al. Cloning of a gene bearing missense mutations in early-onset familial Alzheimer's disease. Nature 1995;375:754-60.

28 Levy-Lahad E, Wasco W, Poorkaj P, et al. Candidate gene for the chromosome 1 familial Alzheimer's disease locus. Science 1995;269:973-7.

29 Rogaev EI, Sherrington R, Rogaeva EA, et al. Familial Alzheimer's disease in kindreds with a missense mutation in a gene on chromosome 1 related to the Alzheimer's disease type 3 gene. Nature 1995;376: 775-8.

30 Strittmatter WJ, Saunders AM, Schmechel D, et al. Apolipoprotein E: high avidity binding to beta-amyloid and increased frequency of type 4 allele in late-onset
familial Alzheimer's disease. Proc Natl Acad Sci USA 1993;90:1977-81.

31 Saunders AM, Strittmatter WJ, Schmechel D, et al. Association of apolipoprotein $\mathrm{E}$ allele epsilon 4 with late-onset familial and sporadic Alzheimer's disease. Neurology 1993;43:1467-72.

32 Chartier-Harlin MC, Parfitt M, Legrain S, et al. Apolipoprotein E, $\varepsilon 4$ allele as a major risk factor for sporadic early and late-onset form of Alzheimer's disease: analysis of the $19 \mathrm{q} 13.2$ chromosomal region. Hum Molec Genet 1994;3:569-74.

33 Van Duijn CM, de Knijff $\mathrm{P}$, Cruts $\mathrm{M}$, et al. Apolipoprotein E $\varepsilon 4$ allele in a population-based study of early-onset Alzheimer's disease. Nature Genet 1994;7: $74-8$.

34 Van Dijk PTM, Dippel DWJ, Habbema JDF. Survival of patients with dementia. I Am Geriatr Soc 1991;39: 603-10

35 Katzman R, Hill LR, Yu ES, et al. The malignancy of dementia. Predictors of mortality in clinically diagnosed dementia in a population survey of Shanghai, China. Arch Neurol 1994;51:1220-5.

36 Chen JY, Stern Y, Sano M, Mayeux R. Cumalative risk of developing extrapyramidal signs, psychosis, or myoclonus in the course of Alzheimer's disease. Arch Neurol 1991;48:1141-3.

37 Risse SC, Lampe TH, Bird TD, et al. Myoclonus, seizures, and paratonia in Alzheimer's disease. Alzheimer Dis Assoc Disord 1990;4:217-25.

38 Knesevich JW, Toro FR, Morris JC, et al. Aphasia, family history, and the longitudinal course of senile dementia of the Alzheimer type. Psychiatry Res 1985;14: 255-63.

39 Molsa PK, Martilla RJ, Rinne UK. Long term survival and predictors of mortality in Alzheimer's disease and multi-infarct dementia. Acta Neurol Scand 1995;91: 159-64

40 Stern Y, Mayeux R, Chen JY, et al. Predictors of mortality in Alzheimer's disease. Ann Neurol 1989;26:132.

41 Kennedy AM, Neuman SK, Frackowiak RS, et al. Chromosome 14 linked familial Alzheimer's disease. A clinico-pathological study of a single pedigree. Brain 1995;118:185-205.

42 Haltia M, Viitanen M, Sulkava R, et al. Chromosome 14encoded Alzheimer's disease: genetic and clinicopathological description. Ann Neurol 1994;36:362-7.

43 Lampe TH, Bird TD, Nochlin D, et al. Phenotype of chromosome 14-linked familial Alzheimer's disease in a large kindred. Ann Neurol 1994;36:368-78.

44 Farrer LA, Cupples LA, Van Duijn CM, et al. Rate of progression of Alzheimer's disease is associated with genetic risk. Arch Neurol 1995;52:918-23.

45 Corder EH, Saunders AM, Strittmatter WJ, et al. Apolipoprotein $\mathbf{E}$, survival in Alzheimer's disease patients, and the competing risks of death and Alzheimer's disease. Neurology 1995;45:1323-8.

46 Basun H, Grut M, Winblad B, Lannfelt L. Apolipoprotein epsilon 4 allele and disease progression in patients with late-onset Alzheimer's disease. Neurosci Lett 1995;183: $32-4$.

47 Frisoni GB, Govoni S, Geroldi C, et al. Gene dose of the epsilon 4 allele of apolipoprotein $\mathrm{E}$ and disease progression in sporadic late-onset Alzheimer's disease. Ann Neurol 1995;37:596-604

48 Van Duijn CM, de Knijff P, Wehnert A, et al. The apolipoprotein $E \varepsilon 2$ allele is associated with an increased risk of early-onset Alzheimer's disease and a reduced survival. Ann Neurol 1995;37:605-10.

49 Pantoni L, Garcia JH. The significance of white matter abnormalities 100 years after Binswanger's report. Stroke 1995;26:1293-301.

50 Tournier-Lasserve E, Joutel A, Melki J, et al. Cerebral autosomal dominant arteriopathy with subcortical infarcts and leukoencephalopathy maps to chromosome 19q12. Nature Genet 1993;3:256-9.

51 Chabriat H, Vahedi K, Iba-Zizen MT, et al. Clinical spectrum of CADASIL: a study of 7 families. Cerebral auto- 
somal dominant arteriopathy with subcortical infarcts and leukoencephalopathy. Lancet 1995;346:934-9.

52 Hier DB, Wallace JD, Gorelick PB, et al. Predictors of survival in clinically diagnosed Alzheimer's disease and multi-infarct dementia. Arch Neurol 1989;46: 1213-6.

53 Van Duijn CM, Stijnen T, Hofman A. Risk factors for Alzheimer's disease: overview of the collaborative reanalysis of case-control studies. Int $\mathcal{F}$ Epidemiol 1991;20 (suppl):S4-12.

54 Van Duijn CM, Clayton D, Chandra V, et al. Familial aggregation of Alzheimer's disease and related disorders: a collaborative re-analysis of case-control studies. Int $\mathcal{F}$ Epidemiol 1991;20 (suppl):S13-20.

55 Rocca WA, van Duijn CM, Chandra V, et al. Maternal age and Alzheimer's disease: a collaborative re-analysis of case-control studies. Int $\mathcal{F}$ Epidemiol 1991;20 (suppl): S21-7.

56 Mortimer JA, van Duijn CM, Chandra V, et al. Head trauma as a risk factor for Alzheimer's disease: a collaborative re-analysis of case-control studies. Int $\mathcal{F}$ Epidemiol $1991 ; 20$ (suppl):S28-35.

57 Breteler MMB, van Duijn CM, Chandra V, et al. Medical history and the risk of Alzheimer's disease: a collaborative re-analysis of case-control studies. Int $\mathcal{f}$ Epidemiol 1991;20(suppl):S36-42.

58 Jorm AF, van Duijn CM, Chandra V, et al. Psychiatric history and related exposures as risk factors for Alzheimer's disease: a collaborative re-analysis of casecontrol studies. Int $\mathcal{F}$ Epidemiol 1991;20(suppl):S43-7.

59 Graves AB, van Duijn CM, Chandra V, et al. Alcohol and tobacco consumption as risk factors for Alzheimer's disease: a collaborative re-analysis of case-control studies. ease: a collaborative re-analysis of case-con

60 Graves AB, van Duijn CM, Chandra V, et al. Occupational exposures to solvent and lead as risk factors for Alzheimer's disease: a collaborative re-analysis of case-control studies. Int $\mathcal{F}$ Epidemiol 1991;20 (suppl): S58-61.

61 Shimano $\mathrm{H}$, Murase T, Ishibashi S, et al. Plasma apolipoproteins in patients with multi-infarct dementia. Atherosclerosis 1989;79:257-60.

62 Frisoni GB, Geroldi C, Bianchetti A, et al. Apolipoprotein $\mathrm{E}$ epsilon 4 allele frequency in vascular dementia and Alzheimer's disease. Stroke 1994;25:1703-4.

63 St Clair D, Norrman J, Perry R, et al. Apolipoprotein E epsilon 4 allele frequency in patients with Lewy body dementia, Alzheimer's disease and age-matched controls. Neurosci Lett 1994;176:45-6.

64 Amouyel P, Vidal O, Launay JM, Laplanche IL. The apolipoprotein $\mathrm{E}$ alleles as major susceptibility factors for Creutzfeldt-Jakob disease. The French Research for Creutzfeldt-Jakob disease. The French Research Group on Epidemiology of Human

65 Reed T, Carmelli D, Swan GE, et al. Lower cognitive performance in normal older adult male twins carrying the apolipoprotein E epsilon 4 allele. Arch Neurol 1994;51: 1189-92.

66 Feskes E, Havekes LM, Kalmijn S, et al. Apolipoprotein E4 allele and congnitive decline in elderly men. $B M F$ 1994;309:1202-6.

67 Henderson AS, Easteal S, Jorm AF, et al. Apolipoprotein E allele E4, dementia and cognitive decline in a population sample. Lancet 1995;346:1387-90.

68 Petersen RC, Smith GE, Ivnik RJ, et al. Apolipoprotein E status as a predictor of the development of Alzheimer's disease in memory-impaired individuals. $¥ A M A 1995$; disease in $\mathrm{m}$

69 Van Gool WA, Evenhuis HM, van Duijn CM, on behalf of the Dutch Study Group on Down's Syndrome and Ageing. A case-control study of apolipoprotein E genotypes in Alzheimer's disease with Down's syndrome. Ann Neurol 1995;38;225-30.

70 Payami H, Montee KR, Kaye JA, et al. Alzheimer's disease, apolipoprotein $\mathrm{E} 4$, and gender (letter). $¥ A M A$ 1994;271:1316-7.

71 Corder EH, Saunders AM, Strittmatter WJ, et al. The apolipoprotein E $\varepsilon 4$ allele and sex-specific risk of Alzheimer's disease. $\mathfrak{F A M A}$ 1995;273:373-74.

72 Jarvik GP, Wijsman EM, Kukull WA, et al. Interactions of apolipoprotein E genotype, total cholesterol level, age, and sex in prediction of Alzheimer's dise
trol study. Neurology 1995;45:1092-6.

73 Hendrie HC, Hall KS, Hui S, et al. Apolipoprotein E genotypes and Alzheimer's disease in a community tudy of elderly African Americans. Ann Neurol 1995;37: $118-20$

74 Maestre G, Ottman R, Stern Y, et al. Apolipoprotein E and Alzheimer's disease: ethnic variation in genotypic risks. Ann Neurol 1995;37:254-59.

75 Hendrie HC, Hall KS, Hui S, et al. Apolipoprotein E genotypes and Alzheimer's disease in a community study of elderly African Americans. Ann Neurol 1995;37: 118-20.

76 Rebeck GW, Perls TT, West HL, et al. Reduced apolipoprotein epsilon 4 allele frequency in the oldest old Alzheimer's patients and cognitively normal individuals Neurology 1994;44:1513-6.

77 Lannfelt L, Lilius L, Nastase M, et al. Lack of association between apolipoprotein $\mathrm{E}$ allele epsilon 4 and sporadic Alzheimer's disease. Neurosci Lett 1994;169:175-8.

78 Sobel E, Louhija J, Sulkava R, et al. Lack of association of apolipoprotein $\mathrm{E}$ allele epsilon 4 with late-onset of apolipoprotein E allele epsilon 4 with late-onset Neurology 1995;45:903-7.
79 Corder EH, Saunders AM, Risch NJ, et al. Protective effect of apolipoprotein $\mathrm{E}$ type 2 allele for late onset Alzheimer disease. Nature Genet 1994;7:180-4.

80 Sorbi S, Nacmias B, Forleo P, et al. ApoE allele frequencies in Italian sporadic and familial Alzheimer's disease. Neurosci Lett 1994;177:100-2.

81 Strittmatter WJ, Roses AD. Apolipoprotein E and Alzheimer disease. Proc Natl Acad Sci USA 1995;92. 4725-7.

82 Holland AJ, Oliver C. Down's syndrome and the links with Alzheimer's disease. I Neurol Neurosurg, Psychiatry 1995;59:111-4.

83 Mendez MF, Underwood KL, Zander BA, et al. Risk factors in Alzheimer's disease: a clinicopathologic study. Neurology 1992;42:770-5.

$84 \mathrm{Li} \mathrm{G}$, Shen YC, $\mathrm{Li} \mathrm{YT}$, et al. A case-control study of Alzheimer's disease in China. Neurology 1992;42: 1481-8.

85 Fratiglioni L, Ahlbom A, Viitanen M, Winblad B. Risk factors for late-onset Alzheimer's disease: a populationbased, case-control study. Ann Neurol 1993;33:258-66.

86 Prince M, Cullen M, Mann A. Risk factors for Alzheimer's disease and dementia: a case-control study based on the MRC elderly hypertension trial. Neurology, 1994 44:97-104.

87 Sadovnick AD, Yee IM, Hirst C. The rate of the Down syndrome among offspring of women with Alzheime disease. Psychiatric Genetics 1994;4:87-9.

88 Forster DP, Newens AJ, Kay DW, Edwardson JA. Risk factors in clinically diagnosed presenile dementia of the Alzheimer type: a case-control study in northern England. $\mathcal{F}$ Epidemiol Comm Health 1995;49:253-8.

89 The Canadian Study of Health and Aging: risk factors for Alzheimer's disease in Canada. Neurology 1994;44: 2073-80.

90 Yatham LN, McHale PA, Kinsella A. Down syndrome and its association with early-onset Alzheimer's disease. Acta Psychiatry Scand 1988;77:38-41.

91 Berr C, Borghi E, Rethore MO, et al. Absence of familia association between dementia of the Alzheimer type and Down syndrome. Am $\mathcal{F}$ Med Genet 1989;33:545-50

92 Schupf $\mathrm{N}$, Kapell $\mathrm{D}$, Lee $\mathrm{JH}$, et al. Increased risk of Alzheimer's disease in mothers of adults with Down's syndrome. Lancet 1994;344:353-6.

93 Van Duijn CM, Clayton DG, Chandra V, et al. Interaction between genetic and environmental risk factors for Alzheimer's disease: a reanalysis of case-control studies. Genet Epidemiol 1994;11:539-51.

94 De Vos RA, Jansen EN, Stam FC et al. 'Lewy body disease': clinico-pathological correlations in 18 consecutive cases of Parkinson's disease with and without dementia. Clin Neurol Neurosurg 1995;97:13-22.

95 Saitoh T, Xia Y, Chen X, et al. The CYP2D6B mutant allele is overrepresented in the Lewy body variant of Alzheimer's disease. Ann Neurol 1995;37:110-2.

96 Chen X, Xia Y, Alford M, et al. The CYP2D6B allele is associated with a milder synaptic pathology in Alzheimer's disease. Ann Neurol 1995;38:653-8.

97 Farrer LA, Cupples LA, Connor L, et al. Association of decreased paternal age and late-onset Alzheimer's disease. Arch Neurol 1991;48:599-604.

98 Mayeux R, Ottman R, Tang MX, et al. Genetic susceptibility and head injury as risk factors for Alzheimer's disease among community-dwelling elderly persons and their first-degree relatives. Ann Neurol 1993;33: and their

99 Rasmussen DX, Brandt J, Martin DB, Folstein MF. Head injury as a risk factor in Alzheimer's disease. Brain Injury 1995;9:213-9.

100 Mayeux R, Ottman R, Maestre G, et al. Synergistic effect of traumatic head injury and apolipoprotein-epsilon 4 in patients with Alzheimer's disease. Neurology 1995;45:555-7.

01 Roberts GW, Gentleman SM, Lynch A, et al. Beta amyoid protein deposition in the brain after severe head injury: implications for the pathogenesis of Alzheimer's disease. I Neurol Neurosurg Psychiatry 1994;57: 419-25.

102 Luchins DJ, Cohen D, Hanrahan P, et al. Are there clinica differences between familial and non-familial

103 Percy ME, Dalton AJ, Markovic VD, et al. Autoimmune thyroiditis associated with mild "subclinical" hypothyroidism in adults with Down syndrome: a comparison of patients with and without manifestations of Alzheimer's disease. Am $₹$ Med Genet 1990;36:140-54.

104 Ewins DL, Rossor MN, Butler J, et al. Association between autoimmune thyroid disease and familial Alzheimer's disease. Clin Endocrinol 1991;35:93-6.

105 Kokmen E, Beard CM, Chandra V, et al. The association between Alzheimer's disease and thyroid disease in Rochester, Minnesota. Neurology 1991;41:1745-7.

106 Skoog I. Risk factors for vascular dementia: a review. Dementia 1994;5:137-44.

107 Verny M, Duyckaerts C, Pierot L, Hauw JJ. Leuko-araiosis. Dev Neurosci 1991;13:245-50.

108 Scheltens P, Barkhof F, Valk J, et al. White matter lesions on magnetic resonance imaging in clinically diagnosed Alzheimer's disease. Evidence for heterogeneity. Brain 1992;115:735-48.

109 Bots ML, van Swieten JC, Breteler MMB, et al. Cerebral white matter lesions and atherosclerosis in the white matter lesions and atherosclero

110 Dash PK, Moore AN. Enhanced processing of APP induced by IL-1 beta can be reduced by indomethacin 
and nordihydroguaiaretic acid. Biochem Biophys Res Commun 1995;208:542 8

111 Brugg B, Dubreuil YL, Huber G, et al. Inflammatory processes induce beta-amyloid precursor protein processes induce beta-amyloid precursor protein 92:3032-5.

112 Breitner JC, Gau BA, Welsh KA, et al. Inverse association of anti-inflammatory treatments and Alzheimer's disease: initial results of a co-twin control study. Neurology 1994;44:227-32.

113 Lucca U, Tettamanti M, Forloni G, Spagnoli A Nonsteroidal antiinflammatory drug use in Alzheimer's disease. Biol Psychiatry 1994;36:854-6.

114 Andersen K, Launer LJ, Ott A, et al. Do nonsteroida anti-inflammatory drugs decrease the risk for Alzheimer's disease? The Rotterdam Study. Neurology 1995;45:1441-5.

115 Beard CM, Kokmen E, Kurland T. Rheumatoid arthritis and susceptibility to Alzheimer's disease. Lancet 1991; 337:1426,

116 Rich JB, Rasmusson DX, Folstein MF, et al. Nonsteroidal anti-inflammatory drugs in Alzheimer's disease. Neurology 1995;45:51-5.

117 Honjo H, Tanaka K, Kashiwagi T, et al. Senile dementiaAlzheimer's type and estrogen. Horm Metab Res 1995 27:204-7.

118 Brenner DE, Kukull WA, Stergachis A, et al. Postmenopausal estrogen replacement therapy and the ris of Alzheimer's disease: a population-based case-control study. Am f Epidemiol 1994;140:262-7.

119 Paganini-Hill A, Henderson VW. Estrogen deficiency and risk of Alzheimer's disease in women. Am $\mathcal{F}$ Epidemio 1994;140:256-61.

120 Henderson VW, Paganini-Hill A, Emanuel CK, et al. Estrogen replacement therapy in older women. Estrogen replacement therpy in disease cases and nomparisons between Alzheimer's disease cases and nondemente

121 Hebert LE, Scherr PA, Beckett LA, et al. Relation of smoking and alcohol consumption to inciden Alzheimer's disease. Am $\mathcal{f}$ Epidemiol 1992;135:347-55.

122 Brenner DE, Kukull WA, van Belle G, et al. Relationship between cigarette smoking and Alzheimer's disease in population-based case-control study. Neurology 1993; 43:293-300.

123 Letenneur L, Dartigues JF, Commenges D, et al. Tobacco consumption and cognitive impairment in elderly people. A population-based study. Ann Epidemiol 1994;4: ple. A pop

124 Lee PN. Smoking and Alzheimer's disease: a review of the epidemiological evidence. Neuroepidemiology 1994;13. 131-44.

125 Van Duijn CM, Havekes LM, Van Broeckhoven C, et al. Apolipoprotein $\mathrm{E}$ genotype and association between smoking and early onset Alzheimer's disease. $B M f$ 1995;310:627-31.

126 Plassman BL, Helms MJ, Welsh KA, et al. Smoking, Alzheimer's disease, and confounding with genes (letter). Lancet 1995;345:387.

127 Nitta A, Katono Y, Itoh A, et al. Nicotine reverses scopolamine-induced impairment of performance in passive avoidance task in rats through its action on the dopamineroic neuronal system. Pharmacol Biochem Behav 1995;49:807-12.

128 Newhouse PA, Potter A, Corwin J, Lenox R. Age-related effects of the nicotinic antagonist mecamylamine on cognition and behavior. Neuropsychopharmacology cognition and

129 Jones GM, Sahakian BJ, Levy R, et al. Effects of acute subcutaneous nicotine on attention, information processing and short-term memory in Al

130 Wilson AL, Langley LK, Monley J, et al. Nicotine patches in Alzheimer's disease: pilot study on learning, memory, and safety. Pharmacol Biochem Behav 1995;51:509-14.

131 Morens DM, Grandinetti A, Reed D, et al. Cigarette smoking and protection from Parkinson's disease: false association or etiologic clue? Neurology 1995;45: 1041-51.

132 Saunders PA, Copeland JR, Dewey ME, et al. Heavy drinking as as risk factor for depression and dementia in elderly men. Finding from the Liverpool longitudinal elderly men. Finding from the Liverpoc

133 Kukull WA, Larson EB, Bowen JD, et al. Solvent exposure as a risk factor for Alzheimer's disease: a case-control sure as a risk factor for Alzheimer's disease:
study. Am $\mathcal{F}$ Epidemiol $1995 ; 141: 1059-71$.

134 Edling C, Ekberg K, Ahlborg G Jr, et al. Long-term follow-up of workers exposed to solvents. Br F Ind Med 1990;47:75-82.

135 Landsberg JP, McDonald B, Watt F. Absence of aluminium in neuritic plaque cores in Alzheimer's disease. Nature 1992;360:65-8.

136 Kawahara M, Muramoto $\mathrm{K}$, Kobayashi $\mathrm{K}$, et al. Aluminum promotes the aggregation of Alzheimer's amyloid beta-protein in vitro. Biochem Biophys Res Commun 1994;198:531-5.

137 Fasman GD Perczel A, Moore CD. Solubilization of beta-amyloid-(1-42)-peptide: reversing the beta-sheet beta-amyloid-(1-42)-peptide: reversing the beta-sheet Conformation induced by aluminum

138 Scott CW, Fieles A, Sygowski LA, Caputo CB. Aggregation of tau protein by aluminum. Brain Res 1993;628: $77-84$

139 Candy JM, McArthur FK, Oakley AE, et al. Aluminium accumulation in relation to senile plaque and neurofibrillary tangle formation in the brains of patients with renal failure. I Neurol Sci 1992;107:210-8.

140 Harrington CR, Wischik CM, McArthur FK, et al. Alzheimer's-disease-like changes in tau protein processing: association with aluminium accumulation in brains of renal dialysis patients. Lancet 1994;343:993-7.

141 Doll R. Review: Alzheimer's disease and environmental survival bias. Age Ageing 1993;22:138-53.

142 Jacqmin $\mathrm{H}$, Commenges $\mathrm{D}$, Letenneur $\mathrm{L}$, et al. Components of drinking water and risk of cognitive impairponents of drinking water and risk of cognitive impair-

143 Rifat SL, Eastwood MR, McLachlan DR, et al. Effect of exposure of miners to aluminium powder. Lancet 1990; 336:1162-5.

144 Crapper McLachlan DR, Dalton AJ, Kruck TP, et al. Intramuscular desferrioxamine in patients with Alzheimer's disease. Lancet 1991;337:1304-8.

145 Edwardson JA, Moore PB, Ferrier IN, et al. Effect of silicon on gastrointestinal absorption of aluminium. Lancet 1993;342:211-2.

146 O'Mahony D, Denton J, Templar J, et al. Bone aluminium content in Alzheimer's disease. Dementia 1995; 6:69-72

147 Zapatero MD, Garcia de Jalon A, Pascual F, et al. Serum aluminium levels in Alzheimer's disease and senile aluminium levels in Alzheimer's disease and

148 Fosmire GJ, Focht SJ, McClearn GE. Genetic influences on tissue deposition of aluminum in mice. Biol Trace on tissue deposition of a

149 Katzman R. Education and the prevalence of dementia and Alzheimer's disease. Neurology 1993;43:13-20.

150 Beard CM, Kokmen E, Offord KP, Kurland LT. Lack of association between Alzheimer's disease and education, occupation, marital status, or living arrangement. Neurology 1992;42:2063-8.

151 Cobb JL, Wolf PA, Au R, et al. The effect of education on the incidence of dementia and Alzheimer's disease in the Framingham Study. Neurology 1995;45: 1707-12.

152 Stern $\mathrm{Y}$, Tang $\mathrm{MX}$, Denaro J, Mayeux R. Increased risk of mortality in Alzheimer's disease patients with more of mortality in Alzheimer's disease patients with more advanced educational

153 Moritz DI Petitti DB. Association of education with reported age of onset and severity of Alzheimer's disease at presentation: implications for the use of clinical samples. Am ₹ Epidemiol 1993;137:456-62. 